[Available from: https://www.invo.org.uk/wp-content/uploads/2016/05/ HRA-INVOLVE-updated-statement-2016.pdf.

[2] Fitzcharles, M.-A., Brachaniec, M., Cooper, L., Dubin, R., Flynn, T., Gerhold, K., Häuser, W., Cowan, K., Laupacis, A., Marleau, R., Milot, M., Szajcz-Keller, N., Sumpton, J., Walsh, Z. \& El-Gabalawy, H. 2017. A paradigm change to inform fibromyalgia research priorities by engaging patients and health care professionals. Canadian Journal of Pain, 1, 137-147.

Acknowledgments: This work was supported by the National Institute for Health research [ICA-PCAF-2018-01-078 to SD]

Disclosure of Interests: Sandra Derham: None declared, Mel Brooke Grant/ research support from: Sponsorship from Lilly to BIRD for the Patient and Public Engagement Programme, Sponsorship from Sanofi to BIRD for the Healthcare Professionals Education Programme.

DOI: 10.1136/annrheumdis-2020-eular.2670

\section{PARE0030 PEER SUPPORT OF PATIENT AND PUBLIC INVOLVEMENT AND ENGAGEMENT IN RESEARCH: THE 'RUG-BUDDY'}

A. Higginbottom ${ }^{1}$, K. Research User Group ${ }^{1}$, C. Rhodes ${ }^{1}$, L. Campbell ${ }^{1}$, S. Blackburn' ${ }^{1}{ }^{1}$ Keele University, School of Primary, Community and Social Care, Keele, United Kingdom

Background: Since 2006, The School of Primary, Community and Social Care, Keele University has a long standing commitment to Patient and Public Involvement and Engagement (PPIE) in research. The School's Research User Group (RUG) has 133 members in January 2020, compared to 80 members in September 2016. Supporting the practical and emotional needs of a growing number of RUG members to support their long-term involvement is of prime importance.

Arising from Keele's role as a test bed site for the new UK Public Involvement Standards, a new peer support role (the 'RUG-Buddy') was co-produced to facilitate the support of RUG members.

Objectives: The RUG-Buddy is a peer support and mentoring scheme. More experienced RUG members attend research meetings with less experienced members to provide support and reassurance. The scheme aims to provide: -A welcoming and friendly environment for RUG members

- Extra support for all RUG members before, during and after research meetings - Help new RUG members ease into public involvement

-Support with discussions between researchers and RUG members, e.g. avoiding research jargon

- Reassurance to new members - learning from those with greater experience of public involvement

-Someone to talk to and confide in from people who have personal experience of PPIE

-Practical advice on completing payment forms, parking issues, etc.

Methods: Peer support is provided by a panel of existing RUG members who have substantial experience of PPIE in research. This is an additional method of supporting the RUG members alongside support provided by the School's PPIE team. RUG-Buddies will be supported in their role by the PPIE team and provided with an induction and training. RUG-Buddies are offered payment for their time and have their travel expenses reimbursed. The RUG-Buddies scheme will be piloted during an initial 6-month period, after which it will be reviewed, with feedback from RUG-Buddies and RUG members.

Results: A role description for the RUG-Buddy role has been coproduced by Keele's PPIE team and its RUG Steering Group (Table 1). A panel of 10 RUG members have been recruited for the RUG-Buddy role and have received an induction and training (e.g. Health and Safety, Information Governance). RUG-Buddies have provided support to and attended research meetings with other RUG members. The RUG-Buddy role will be reviewed in September 2020.

Table 1. Summary of the RUG-Buddy role description

\begin{tabular}{lcc}
\hline Qualities of a RUG-Buddy & $\begin{array}{c}\text { RUG-Buddy } \\
\text { responsibilities }\end{array}$ & PPIE team responsibilities \\
\hline $\begin{array}{l}\text { Willing to share personal } \\
\text { experience }\end{array}$ & $\begin{array}{c}\text { To attend up to the first } \\
\text { three PPIE meetings of a } \\
\text { research project }\end{array}$ & $\begin{array}{c}\text { To provide a training session for } \\
\text { all RUG-Buddies }\end{array}$ \\
Friendly and approachable & $\begin{array}{c}\text { To introduce new member } \\
\text { to RUG members and } \\
\text { research team }\end{array}$ & $\begin{array}{c}\text { To meet RUG-Buddies every } \\
\text { two months to provide review/ } \\
\text { feedback of the role }\end{array}$ \\
$\begin{array}{l}\text { Enthusiastic and knowledgea- } \\
\text { ble about PPIE in research }\end{array}$ & $\begin{array}{c}\text { To encourage contribution } \\
\text { to the meeting }\end{array}$ & $\begin{array}{c}\text { To have a named PPIE lead } \\
\text { for any questions/queries that } \\
\text { may arise }\end{array}$
\end{tabular}

Table 1. Summary of the RUG-Buddy role description

\begin{tabular}{lcc}
\hline Qualities of a RUG-Buddy & $\begin{array}{c}\text { RUG-Buddy } \\
\text { responsibilities }\end{array}$ & PPIE team responsibilities \\
\hline Be reliable and punctual & $\begin{array}{c}\text { To provide support and } \\
\text { respond to RUG members' } \\
\text { questions }\end{array}$ & $\begin{array}{c}\text { To work alongside RUG-Buddy } \\
\text { to meet and greet public } \\
\text { members }\end{array}$ \\
\hline
\end{tabular}

Conclusion: The RUG-Buddy is an innovative peer support scheme to support the involvement of patients and the public in research. The support provided by RUG-Buddies offers a different perspective from people with real-life experience of involvement in research. It is anticipated that this additional support will enrich the experience of RUG members and facilitate a more welcoming and conducive environment for active and meaningful public involvement. Furthermore, it has also provided an opportunity for the RUG-Buddies to gain valuable new skills and also give something back to the PPIE team and researchers who have supported their own involvement for many years.

Acknowledgments: This project is funded by the National Institute for Health Research (NIHR) School for Primary Care Research (project reference 440). Thank you to the Keele Research User Group for all their great work

Disclosure of Interests: None declared

DOI: 10.1136/annrheumdis-2020-eular.3475

\section{PARE0031 AN MHEALTH TOOL FOR SHARED DECISION MAKING FOR PATIENTS WITH RHEUMATISM AND ARTHRITIS}

Y. Koumpouros ${ }^{1}$, A. Pappa ${ }^{2} .{ }^{1}$ University of West Attica, Informatics and Computer Engineering, Aigaleo, Greece; ${ }^{2}$ Hellenic League Against Rheumatism - ELEANA, Athens, Greece

Background: Patient empowerment is a key element of patient-centred healthcare according to $\mathrm{WHO}$. In the same direction, the Institute of Medicine in the United States supports actions to engage patients in their health care decision in a new patient-centered care model. Patient-centred care models have demonstrated better quality of care as well as potential long-term cost-efficiencies. However, nowadays, many patients are still struggling to become equal partners in care. Patients with chronic conditions, such as rheumatoid arthritis, are often referred to as the most under-used resource in the health system. Shared decision making is a collaborative process enabling a clinician and patient to participate jointly in making a health decision about the treatment having discussed the options, benefits and harms, while considering also the patient's values and experiences.

Objectives: The objective of the current research was to design a tool that will facilitate the shared decision making regarding the treatment approach, based on real life evidences from the patient. The focus of the application is on the pain assessment of patients suffering from rheumatism and arthritis. The proposed solution utilizes the latest technological innovations to support patients and clinicians on their decisions and assessment strategy on a more accurate base.

Methods: The design process followed a user-centered approach by involving a multidisciplinary team of experts (an mHealth expert, a behavioural scientist, and two physicians). An iterative design process focused on the different end-users (patients and clinicians) and their actual needs on the topic concerned. In each phase, the experts involved the end-users to create a highly usable tool. The aim was to capture and address the whole user experience. An evaluation phase took place for three months.

Results: The design team brought the users into every stage of the design process. Twenty patients and three physicians (one pathologist, one general surgeon and an expert in pharmacology and clinical pharmacology) participated and evaluated the modules implemented. The final solution consists of an application running on Android operating system in any smart phone. The final application supports the patient to enter all necessary information about: (i) the pain he/she is feeling, (ii) the medication he/she is receiving, and (iii) his/her life style.

Conclusion: After a three months period of continuous use of the application from the participants during the evaluation phase, they reported very encouraging results. In terms of usage, the patients found it user friendly, easy to learn, easy to use, and easily accessible. They also consider it really useful in order to keep track of their progress and assess the treatment and medications they receive relevant to the pain they feel. The physicians involved in the evaluation of the application found it very useful and with significant potential for daily use by clinical staff to evaluate the therapies given to their patients. All users concluded that the developed app can help towards a more accurate and acceptable treatment based on shared decision, exploiting the collected evidences. 
References:

[1] Angelmar R, Bermann BP. Patient empowerment and efficient health outcomes. Financing sustainable healthcare in Europe. 2007:139-162.

[2] Hargraves IG, Montori VM, Brito JP, et al. Purposeful SDM: A problem-based approach to caring for patients with shared decision making. Patient Education and Counseling. 102(10), 2019, p. 1786-1792.

[3] Légaré $F$, Stacey $D$, Brière $N$, et al. Healthcare providers' intentions to engage in an interprofessional approach to shared decision-making in home care programs: a mixed methods study. J Interprof Care 2013; 27 : 214-222

[4] McWilliams DF, Walsh DA. Pain mechanisms in rheumatoid arthritis. Clin Exp Rheumatol. 2017 Sep-Oct;35 Suppl 107(5):94-101.

[5] National Research Council. Crossing the quality chasm: a new health system for the 21st century. Washington, DC: National Academies Press, 2001.

[6] Hoffmann TC, Légaré F, Simmons MB, et al. Shared decision making: what do clinicians need to know and why should they bother? Med J Aust 2014; 201 (1): 35-39.

Disclosure of Interests: None declared

DOI: 10.1136/annrheumdis-2020-eular.233

\section{PARE0032 STRENGTHENING SELF-MANAGEMENT TO IMPROVE THE QUALITY OF LIFE AND HEALTH STATUS OF PATIENTS WITH INFLAMMATORY ARTHRITIS AND OSTEOPOROSIS IN SWITZERLAND}

A. Mueller ${ }^{1}$, M. Roffler ${ }^{1} .{ }^{1}$ Swiss League against Rheumatism, Zürich, Switzerland

Background: Previous UK studies suggest that people with arthritis taking part in self-management programmes feel more confident in their ability to manage and control their symptoms. These patients may also visit the doctor less frequently and have shown improved physical and clinical outcomes (1, 2). Based on this evidence, self-management has become an essential component of care for patients with arthritis, or generally with chronic diseases. However, there is still a huge gap regarding such self-management services and support programmes in rheumatology in Switzerland.

In the Swiss National Strategy "Musculoskeletal Diseases" 2017-2022, strengthening patients' empowerment is one of the main strategic pillars. Considering that approximately 500,000 people are suffering in Switzerland from inflammatory arthritis (IA) and osteoporosis (OP) alone, there is huge potential to strengthen patients' self-management capacity and thus improve their quality of life (3).

Therefore, the SLR has developed a self-management programme for IA and OP patients. In this programme medical assistants in outpatient rheumatology clinics are trained to consult patients in self-management. This programme is part of a two-year pilot project (2019-2020) that is supported by a consortium of important stakeholders in rheumatology in Switzerland.

Objectives: The ultimate objective is to increase the quality of life and the health status of people with IA and OP in Switzerland by enhancing their capacity for self-management. Furthermore, this pilot project aims at closing an important gap in the Swiss healthcare system by creating an innovative model that can potentially be replicated for other chronic diseases.

Methods: To measure the quality of life, the health status as well as the change in behaviour in patients, the study design includes both qualitative and quantitative methods. Patients enrolled in the programme are asked to answer a questionnaire at three points in time; at enrolment, after the last session and two months after completing the programme. It is expected that at least 45 patients will be enrolled. For a qualitative assessment, in-depth interviews will be conducted with rheumatologists and their medical assistants as well as some of the programme participants.

The training material for the medical assistants was developed by the SLR and will be evaluated by the programme participants. All patients will also evaluate the quality of the consulting provided by the medical assistant, answering a questionnaire after the last session.

Results: Within the first year of implementation, ten outpatient clinics, with twenty-four rheumatologists and twelve medical assistants, were enrolled in the pilot project. Four medical assistants were trained in 2019 and eight are in the process of receiving training in spring 2020. Only after the completion of training will patients be enrolled in the self-management programme. Therefore, outcome-related results cannot be expected until the beginning of 2021
Conclusion: This pilot project provides an innovative approach to closing an important gap in the Swiss healthcare system and to providing a missing component of care for patients with IA and OP. However, it has been challenging to enrol enough clinics in the pilot project. The way the programme is embedded in the current healthcare system, it demands a cultural change within outpatient clinics, allowing medical assistants to step into a new role as consultant.

References:

[1] Barlow JH, Turner, Wright (2000). 'A randomised controlled study of the arthritis self-management programme in the UK' Health Ed Res 15(6): 665-80.

[2] De Silva, D. (2011). Evidence: Helping people help themselves. A review of the evidence considering whether it is worthwhile to support self-management. The Health Foundation. London.

[3] Swiss League against Rheumatism (2017). Swiss National Strategy 'Musculoskeletal Diseases' 2017-2022. Zurich: 10-13.

Disclosure of Interests: None declared

DOI: 10.1136/annrheumdis-2020-eular.5220

\section{SATURDAY, 06 JUNE 2020 \\ Psychosocial support}

\section{PARE0033 \\ I'M HERE BUT I'M NOT: A PHOTOVOICE STUDY OF THE LIVED EXPERIENCE OF SELF-MANAGING RHEUMATOID ARTHRITIS}

S. Donnelly ${ }^{1,2}$, T. Kroll ${ }^{1}$, H. Mannan ${ }^{1}$, C. DIX ${ }^{3}$, A. G. Wilson ${ }^{2} .{ }^{1}$ University College Dublin, Centre for Interdisciplinary Research Education and Innovation in Health Systems, Dublin, Ireland; ${ }^{2}$ University College Dublin, Centre for Arthritis Research, Dublin, Ireland; ${ }^{3}$ Independent filmmaker, Dublin, Ireland

Background: Rheumatoid arthritis (RA) is a widespread chronic disease affecting about $1 \%$ of the population in the West. It is characterised by pain, fatigue and inflammation that can flare-up without warning. This makes the condition difficult to predict and manage. Bury (1982) introduced the concept of chronic illness as a disruptive experience to one's self-identity. This is often an invisible part of managing the illness and taken for granted by others, such as family members, friends and health care professionals. Thus, there is a need to raise awareness of the patients' lived experiences of self-managing this long-term chronic illness.

Objectives: We aimed to collaborate with people with RA to (i) record and reflect the community's strengths and concerns; (ii) raise awareness of the lived experience of self-managing RA (iii) spark a dialogue among key stakeholders around the self-management of RA.

Methods: A purposeful sample of people with RA ( $n=12)$ was recruited. An innovative qualitative methodology, Photovoice, was used (Wang \& Burris, 1997) A series of small group workshops took place. Participants were provided with cameras and appropriate training. They were asked to take photographs of the "challenges and solutions to living with RA" over approximately two weeks. Semi-structured interviews were conducted incorporating photo elicitation. As a group, the participants, a visual artist and researcher co-created a photo exhibition for the public

Results: Participants selected 32 photographs for the exhibition. They carried out a thematic analysis of the photos identifying four themes:

-I'm Here but I'm Not - this theme reflected feelings of alienation and social isolation.

-Medicine in all its forms - this theme captured attitudes towards medication and devices, as well as the creative ways people coped with RA.

-Visible illness - this concerned the recognition of RA. It captures the experience of RA as a "contested illness" and the challenge of gaining medical and cultural legitimacy.

-Mind yourself - this theme highlighted the value of self-care, often closely connected with the natural world and engagement with social activities.

Exhibitions were held at a community arts centre and a large central hospital in Dublin city. A plain language report was also collaboratively produced

Conclusion: This study shows how participatory methods can be used to explore the hidden experience of living with an invisible illness. This research design enabled participants to use photographs to reflect on their experiences and the meaning they intended to convey, thereby increasing trustworthiness of the findings through individual and group member checking. This 